\title{
MONETARY DISCRETION BY FISCAL MEANS: THE CASE OF BULGARIA Preslav Dimitrov ${ }^{1}$, Ivan Todorov ${ }^{2}$, Stoyan Tanchev ${ }^{3}$, Petar Yurukov ${ }^{4}$
}

\begin{abstract}
The specific design of the Bulgarian currency board arrangement (CBA), which provides an opportunity to the Bulgarian government to conduct discretionary monetary policy by changes in the fiscal reserve, was analyzed. The impact of government deposit fluctuations on the dynamics of reserve money and interbank interest rates was investigated. The hypotheses of an automatic adjustment mechanism and a liquidity effect under the Bulgarian currency board arrangement were tested. The methodology employed was a vector autoregression, which included the following variables: MB monetary base; BP - balance of payments; GD - government deposit on the balance sheet of the Issue Department of the Bulgarian National Bank; MRR - minimum required reserve ratio of commercial banks. The target variable was MB. Monthly data for the period January 1998 - December 2018 were used. The study results did not provide evidence of a statistically significant impact of changes in government deposit on reserve money and interbank interest rates. The hypotheses for the existence of an automatic adjustment mechanism and a liquidity effect did not find an empirical confirmation.
\end{abstract}

JEL Classification Numbers: E42, E52, E62, DOI: 10.12955/cbup.v7.1341

Keywords: Bulgaria, currency board arrangement, automatic adjustment mechanism, liquidity effect

\section{Introduction}

This study has three objectives. The first objective is to check whether the automatic link between the balance of payments dynamics and the dynamics of the monetary base, typical of the "hard" firstgeneration CBAs, exists in the "soft" Bulgarian CBA of the second generation. The second objective is to find out how the inclusion of the government deposit in the BNB Issue Department liabilities affects the dynamics of the monetary base. The third objective is to test the hypothesis of the existence of liquidity effect (influence of changes in the government deposit on the money market interest rates) under the conditions of the Bulgarian currency board.

In the first generation of hard CBAs, the dynamics of the monetary base is determined entirely by the balance of payments dynamics. If there is no possibility to change the level of coverage of the monetary base with international reserves or the level of the minimum reserve requirements of commercial banks, then there are no factors causing deviations from the long-term equilibrium between the balance of payments and the monetary base. In order to have a long-term equilibrium relationship (cointegration) between the balance of payments and the monetary base, both time series must be integrated of order one I (1) and a stationary linear combination must exist between their level values.

There are five factors that may cause deviations from the long-term equilibrium between the balance of payments and the monetary base: the preservation of the lender of last resort (LLR) function, the change in minimum reserve requirements (MRR), the methodology for accounting for these reserves, the inclusion of a government deposit in the liabilities of the Issue Department, and the lack of IMF (and other international financial sources) financing in the balance of payments financial account. For the entire period of existence of the currency board arrangement in Bulgaria (1997-2018), the BNB did not act as an LLR, changed the amount of the MRR only three times (in July 2000, September 2007 and December 2008) and since 2007 has not used IMF funding. It can be assumed that the main cause of deviations from the long-term equilibrium between the monetary base and the balance of payments in the Bulgarian currency board is the fiscal reserve (the government deposit in the liabilities of the BNB Issue Department balance sheet).

Cointegration and error correction models are widely used in research for the existence of a long-term equilibrium link between variables (Nenovsky and Hristov, 1998; Nenovsky, Hristov, and Mihaylov, 2001; Nenovsky and Hristov, 2002; Petrov, 2000 etc.). A main feature of the cointegrated variables is that their dynamics depend on the size of any deviation from the long-term equilibrium. In order for

\footnotetext{
${ }^{1}$ South-West University "Neofit Rilski”, Faculty of Economics, Blagoevgrad, Bulgaria, preslav.dimitrov@swu.bg

${ }^{2}$ South-West University "Neofit Rilski”, Faculty of Economics, Blagoevgrad, Bulgaria, ivank.todorov@swu.bg

${ }^{3}$ South-West University "Neofit Rilski”, Faculty of Economics, Blagoevgrad, Bulgaria, stoyan_tanchev@swu.bg

${ }^{4}$ South-West University "Neofit Rilski”, Faculty of Economics, Blagoevgrad, Bulgaria, petaryurukovofficial@gmail.com
} 
the system to return to its long-term equilibrium, the movement of some of its variables must respond to the size of the imbalance. According to the Nenovsky and Hristov (2002) definition of the automatic adjustment mechanism under a currency board arrangement, the existence of cointegration between the balance of payments and the monetary base is evidence of the smooth operation of this mechanism. The absence of cointegration is a sign of malfunctioning of the automatic mechanism and existence of discretion. The variables reflecting the discretionary policy options are the government's fiscal deposit with the BNB and the size of the MRR of the commercial banks.

The goals of the research ware achieved by the fulfillment of the following tasks:

- Review of the literature on the Bulgarian currency board arrangement (section one);

- Investigation of the theoretical foundations of the automatic adjustment mechanism and liquidity effect under a currency board arrangement (section two);

- Empirical analysis of the automatic adjustment mechanism of the Bulgarian currency board arrangement (section three);

- Empirical study of the impact of the changes in the government deposit on the money market (section four).

\section{Literature review}

Bulgaria's CBA is heavily debated in economic literature (Avramov, 1999; Carlson \& Valev, 2001; Chobanov \& Nenovsky, 2004; Desquilbet \& Nenovsky, 2004; Dobrev, 1999; Fabris \& Rodic, 2013; Hardouvelis \& Monokrousos, 2009; Hristov, 2004; Ialzanov \& Nenovsky, 2001; Marinova, 2016; Miller, 1999; Minassian, 2018; Moheeput, 2008; Nenovsky \& Dimitrova, 2002; Nenovsky \& Hristov, 2002; Nenovsky, Hristov \& Mihaylov, 2002; Todorov, 2013). Hanke and Schuler (1991) suggested that a currency board be introduced in Bulgaria in order to achieve a convertibility of the Bulgarian lev into foreign currency. This proposal was implemented on 1 July 1997 following a severe financial crisis involving bank failures and a serious internal and external depreciation of the Bulgarian lev.

Avramov (1999) reviewed the common features of the CBAs, their internal and external vulnerability, the peculiarities of the Bulgarian CBA and possible exit strategies.

Miller (1999) analyzed the first two years of the functioning of the currency board in Bulgaria in terms of its organizational structure and the strengths and weaknesses characteristic of the currency boards.

Dobrev (1999) focused on the specifics of monetary policy, financial system and management of foreign exchange reserves under the conditions of the Bulgarian currency board.

Ialzanov and Nenovsky (2001) discussed the advantages and disadvantages of maintaining the currency board until Bulgaria enters the Eurozone. As an alternative to the currency board, the authors offered the so-called Euroization (the introduction of the euro in Bulgaria unilaterally or on the basis of a bilateral agreement before Bulgaria's entry to the European Monetary Union).

Carlson and Valev (2001) explored the effects of change of the exchange rate regime in 1997 on the inflation expectations in Bulgaria. The authors found that the introduction of a currency board had lowered inflationary expectations, but to varying degrees for individual business agents.

Nenovsky and Hristov (2002) empirically tested the options for discretionary monetary policy under the conditions of the Bulgarian currency board, which is part of the new generation of currency boards. The authors concluded that there were such options under the Bulgarian currency board and that the automatic adjustment mechanism, characteristic of the orthodox CBAs, did not work.

Nenovsky and Dimitrova (2002) examined the sources and dynamics of inflation in Bulgaria. They found a dynamic but not static Balassa-Samuelson effect. The authors concluded that the main factors of the inflation dynamics in Bulgaria under the currency board are imported inflation and temporary differences between money supply and demand for money.

Nenovsky, Hristov and Mihaylov (2002) performed a comparative and descriptive analysis of the currency boards in Bulgaria, Estonia and Lithuania. Their conclusions were that the three CBAs did not function in a similar way and differed significantly in the reasons for their introduction, their institutional design and their available macroeconomic instruments.

Hristov (2004) tried to empirically answer the question whether the flexibility of macroeconomic instruments in Bulgaria to deal with external shocks would have been greater in a classical central bank than in a currency board arrangement. Hristov concluded that conditions for an effective discretionary monetary policy of a classical central bank in Bulgaria during the period 1997-2004 did 
not exist for two reasons: first, the economic dynamics during this period was determined mainly by structural rather than by cyclical factors and second, there is no confidence of economic agents in discretionary monetary policy.

Desquilbet and Nenovsky (2004) compared the Gold Standard and the Currency Board as monetary regimes with a high degree of confidence in monetary authorities and an automatic adjustment mechanism. The authors made two important conclusions: first, the credibility of the Gold Standard was determined by endogenous factors, and in the currency board by exogenous factors, and second, asymmetries in economic adjustment are much higher in the currency board than in the Gold Standard. Chobanov and Nenovsky (2004) analyzed empirically the liquidity of the money market in Bulgaria under a currency board. The imbalances in the Bulgarian money market could not be overcome by adjusting interest rates, as in hard CBAs, but required management of government reserves in the Central Bank balance sheet. This management allows the government to pursue a discretionary monetary policy by fiscal means.

Moheeput (2008) explored the CBAs in the context of a comprehensive analysis of the problems of choosing a currency-exchange regime. The author claimed that currency boards were created for three reasons: first, to quickly deal with financial chaos, second, as part of the medium-term stability program and third, as a long-term monetary strategy. The currency board in Bulgaria was created for the first reason - as an urgent measure to overcome a severe financial crisis and a loss of confidence in the monetary authorities.

Hardouvelis and Monokrousos (2009) and Todorov (2013) explored the stability of the Bulgarian currency board. The conclusions of both studies were that the Bulgarian currency board was stable, and the most likely scenario was to maintain it until Bulgaria entered the Eurozone.

Fabris and Rodic (2013) analyzed the effectiveness of CBAs as fixed exchange rate regimes compared to floating exchange rates. The current account deficit, measured as a percentage of GDP, and the rate of inflation were higher in currency board countries than in countries with floating exchange rates, indicating poor performance of the currency board as a form of exchange-rate regime.

Marinova (2016) compared monetary and fiscal policy in the Eurozone and Bulgaria. The author asserted that the main risks to the stability of public finances in Bulgaria and the Euro area were political: the frequent change of governments in Bulgaria and the lack of fiscal discipline in the currency union.

According to Minassian (2018), the currency board provided financial stability, but became an obstacle to economic growth in Bulgaria. The author recommended a change of the exchange rate regime in order to stimulate the growth and convergence of the Bulgarian economy with the developed economies of the Eurozone.

The above-mentioned studies can be classified according to different criteria such as methodology, territorial scope and conclusions.

According to their methodology, the examined studies can be divided into being predominantly theoretical and predominantly empirical. The theoretical element dominates in the research of Avramov (1999), Desquilbet and Nenovsky (2004), Dobrev (1999), Ialzanov and Nenovsky (2001), Miller (1999), Moheeput (2008) and Nenovsky, Hristov and Mihaylov (2002). Mostly empirical are the investigations of Carlson and Valev (2001), Chobanov and Nenovsky (2004), Fabris and Rodic (2013), Hardouvelis and Monokrousos (2009), Hristov (2004), Marinova (2016), Minassian (2018), Nenovsky and Dimitrova (2002), Nenovsky and Hristov (2002) and Todorov (2013).

According to their territorial scope, the reviewed sources can be grouped by research on one country and research on more than one country. The first group includes the investigations of Avramov (1999), Carlson and Valev (2001), Chobanov and Nenovsky (2004), Dobrev (1999), Hardouvelis and Monokrousos (2009), Hristov (2004), Ialzanov and Nenovsky (2001), Minassian (2018), Miller (1999), Nenovsky and Dimitrova (2002), Nenovsky and Hristov (2002) and Todorov (2013). The second group consists of the analyses of Desquilbet and Nenovsky (2004), Fabris and Rodic (2013), Marinova (2016), Moheeput (2008) and Nenovsky, Hristov and Mihaylov (2002).

According to their findings, the above examined sources can be divided into studies that recommend the introduction or retention of the CBAs and studies that advocate their removal. The first group includes Avramov (1999), Hardouvelis and Monokrousos (2009), Hristov (2004), Ialzanov and 
Nenovsky (2001), Miller (1999), Nenovsky and Hristov (2002) and Todorov (2013) among others whilst the second group includes Fabris and Rodic (2013) and Minassian (2018) among others.

Four important conclusions can be drawn from the review and the systematization of literature on the currency board in Bulgaria. First, there is a balance between theory and empirics in research. Second, there is no universal optimum currency-exchange regime. The optimum exchange rate regime is determined by specific circumstances and varies by time and country. Third, while in earlier examinations the dominant view was that the currency board in Bulgaria operated successfully and had to be preserved, the number of surveys recommending a change in the currency-exchange regime of Bulgaria has increased in recent years. Fourth, in terms of the problems analyzed, the methodology employed, and the conclusions reached, this paper is similar but not identical to the investigations of Nenovsky and Hristov (1998), Nenovsky and Hristov (2002) and Nenovsky, Hristov and Mihaylov (2001).

\section{Theoretical foundations of the automatic adjustment mechanism and liquidity effect under a currency board arrangement}

The automatic adjustment mechanism under a currency board arrangement can be defined as "a procedure in which for a period of time the dynamics of the monetary base follows the dynamics of the balance of payments and any deviation from this parallel and synchronous movement is relatively fast and automatically corrected, to restore the functioning of the mechanism "(Nenovsky and Hristov, 2002). From an econometric point of view, this means that there must be a cointegration link between the time series.

At this stage, an important methodological and terminological explanation should be made. An automatic mechanism can only be spoken of if there is a link between the balance of payments and the monetary base without any variables for the discretionary policy in the model. If there is a relationship between the balance of payments and the monetary base, and variables for discretionary policy (in the short- or long-term dynamics) are included in the model, we cannot speak of a pure functioning of the automatic mechanism, but rather of a discretionary (or combined) adjustment by automatic mechanism and discretion) (Nenovsky, Hristov and Mihaylov, 2002).

Miller detected significant deviations from the automatism in the functioning of the Bulgarian currency board. He noted that the balance of payments deficit did not automatically reduce the monetary base. This deviation from the principles of the hard currency board is due to the specific design of the Bulgarian currency board (Miller, 1999).

A hard currency board excludes monetary policy and is a specific form of monetary constitution. As the assets in the Issue Department's balance sheet are only international but not domestic, the dynamics of the monetary base depends only on the changes in international foreign exchange reserves that arise from the balance of payments position. As it is well known from the experience of stabilization programs based on fixed exchange rates, the responsibility for macroeconomic management falls entirely on fiscal policy. The design of the Bulgarian Currency Board includes, either deliberately or not, the opportunity for the government to pursue monetary policy through its deposit in the liabilities of the Issue Department. It can definitely be said that there is a specific transmission mechanism through which fiscal policy directly affects the monetary base and indirectly the interest rates. A significant effect of fiscal policy on the liquidity under a CBA was found by Nenovsky, Hristov and Mihaylov (2001).

In a simple way, the Issue Department's balance sheet can be presented as follows. Assets consist of the foreign exchange reserves FER. Liabilities include the notes and coins in circulation C, the total reserves of commercial banks R, the government deposit GD and the deposit of the Banking Department BDD. The total reserves of commercial banks are a sum of their required minimum reserves and excessive reserves. The deposit of the Banking Department is the net value of the currency board. If $\mathrm{MB}$ is the monetary base, then

(1) $\mathrm{MB} \equiv \mathrm{C}+\mathrm{R} \equiv \mathrm{FER}-\mathrm{GD}-\mathrm{BDD}$

The government deposit shows the revenues and the expenditures of the government as well as its loans. If TR is tax revenue, GE - current and investment expenditure of the government, PR privatization revenue, $\mathrm{dBn}$ - net value of the financing by securities, and dIMF - the value of the IMF tranches, then the government deposit is equal to 
(2) $\mathrm{GD}=\mathrm{TR}-\mathrm{GE}+(-\mathrm{PR}-\mathrm{dBn}-\mathrm{dIMF})$

Thus the money supply MS derives the classical form

(3) $\mathrm{MS}=\mathrm{mMB}=\mathrm{m}[\mathrm{FER}-(\mathrm{TR}-\mathrm{GE}-\mathrm{PR}-\mathrm{dBn}-\mathrm{dIMF})-\mathrm{BDD}]$

where $\mathrm{m}$ is the monetary multiplier $(\mathrm{m}>0)$. Then

(4) $\mathrm{MS}=\mathrm{mMB}=\mathrm{m}[\mathrm{FER}-\mathrm{TR}+\mathrm{GE}+\mathrm{PR}+\mathrm{dBn}+\mathrm{dIMF}-\mathrm{BDD}]$

The movements of revenue and expenditure directly affect the monetary base and indirectly the money supply. A decline in tax revenue causes an automatic monetary expansion and vice versa, an increase in tax revenue leads to a monetary contraction. Increasing government spending creates an expansion of the monetary base and vice versa, restraining government spending leads to a contraction in money supply. The private derivative of the privatization revenue can be positive or negative since the privatization consists of two financial components - internal funds and foreign capital. In the first case, there is a contraction of the monetary base and an increase in fiscal reserves, resulting in a negative private derivative. In the second case, the privatization through foreign capital affects the financial account of the balance of payments and may lead to an increase in money supply. In general, the dynamics of the government deposit synthesizes not only fiscal but also monetary policy. In a sense, it can be concluded that the two policies are combined into a syncretic whole. This syncretic policy may have a strong discretionary nature and replace the discretion of the classical central bank (Nenovsky and Hristov, 2002).

The currency board's automatic mechanism works best when currency base fluctuations follow balance-of-payment fluctuations. Stabilization is interpreted as a low variance in the supply of reserve currency. Interesting is the question under what circumstances the government deposit in the currency board has a stabilizing role. This question can be answered by comparing the variances of the monetary base with and without a government deposit in the currency board liabilities (Gulde, 1999).

In fact, two balance sheets of the Issue Department are compared - one without, and the other with a government deposit. In the latter case, the government's fiscal reserves are added to both sides of the balance sheet, with the deposit in liabilities becoming part of the currency board assets (the foreign exchange reserves).

The Issue Department's balance sheet without a government deposit looks like this: the assets consist of FER and the liabilities include C, R, and BDD. The Issue Department's balance sheet with a government deposit looks as follows: FER and GD are the assets, and C, R, GD, and BDD are the liabilities.

In order to have a stabilizing role of GD in the balance sheet, the variance of changes in the monetary base in the first balance sheet should be higher than in the second balance sheet. The variance of the monetary base in both cases can be expressed as

(5) $\operatorname{var}(\triangle \mathrm{FER})=\operatorname{var}(\Delta \mathrm{MB}+\Delta \mathrm{BDD})$

(6) $\operatorname{var}(\Delta \mathrm{FER}+\Delta \mathrm{GD})=\operatorname{var}(\Delta \mathrm{MB}+\Delta \mathrm{BDD}+\Delta \mathrm{GD})$

Equation (5) shows the situation in the hard currency board when the variance of foreign exchange reserves is equal to the variance of the sum of the changes in the monetary base and the changes in the surplus of the monetary base (deposit of the Banking Department). The government deposit is added to both sides of Equation (6). Equations (5) and (6) are combined to obtain the variance of changes in the monetary base $\triangle \mathrm{MB}$.

It follows from Equation (5) that $\operatorname{var}(\Delta \mathrm{FER})=\operatorname{var}(\Delta \mathrm{MB})+\operatorname{var}(\Delta \mathrm{BDD})+2 \operatorname{cov}(\Delta \mathrm{MB}, \Delta \mathrm{BDD})$. Hence, (7) $\operatorname{var}(\Delta \mathrm{MB})=\operatorname{var}(\Delta \mathrm{FER})-\operatorname{var}(\Delta \mathrm{BDD})-2 \operatorname{cov}(\Delta \mathrm{MB}, \Delta \mathrm{BDD})$

It follows from Equation (6) that $\operatorname{var}(\Delta \mathrm{FER})+\operatorname{var}(\Delta \mathrm{GD})+2 \operatorname{Cov}(\Delta \mathrm{FER}, \Delta \mathrm{GD})=\operatorname{var}(\Delta \mathrm{MB})+$ $\operatorname{var}(\Delta \mathrm{BDD})+\operatorname{var}(\Delta \mathrm{GD})+2 \operatorname{cov}(\Delta \mathrm{MB}, \Delta \mathrm{BDD})+2 \operatorname{cov}(\Delta \mathrm{MB}, \Delta \mathrm{GD})+2 \operatorname{cov}(\Delta \mathrm{GD}, \Delta \mathrm{BDD})$.

Then,

(8) $\operatorname{var}(\Delta \mathrm{MB})=\operatorname{var}(\Delta \mathrm{FER})+\operatorname{var}(\Delta \mathrm{GD})+2 \operatorname{cov}(\Delta \mathrm{FER}, \Delta \mathrm{GD})-\operatorname{var}(\Delta \mathrm{BDD})-\operatorname{var}(\Delta \mathrm{GD})-$ $2 \operatorname{cov}(\Delta \mathrm{MB}, \Delta \mathrm{BDD})-2 \operatorname{cov}(\Delta \mathrm{MB}, \Delta \mathrm{GD})-2 \operatorname{cov}(\Delta \mathrm{GD}, \Delta \mathrm{BDD})$

The condition for stabilization is $\operatorname{var}(\Delta \mathrm{MB})$ in Equation (8) to be lower than $\operatorname{var}(\Delta \mathrm{MB})$ in Equation (7). After transformation

(9) $2 \operatorname{cov}(\Delta \mathrm{FER}, \Delta \mathrm{GD})-2 \operatorname{cov}(\Delta \mathrm{MB}, \Delta \mathrm{GD})-2 \operatorname{cov}(\Delta \mathrm{BDD}, \Delta \mathrm{GD})<0$ 
Equation (9) can be presented as $\rho \Delta$ FER $\Delta$ GD $\sigma \Delta$ FER $\sigma \Delta$ GD $-\rho \Delta \mathrm{MB} \Delta$ GD $\sigma \Delta \mathrm{MB} \sigma \Delta \mathrm{GD}-\rho \Delta \mathrm{MB}$ $\Delta \mathrm{GD} \sigma \Delta \mathrm{MB} \sigma \Delta \mathrm{GD}<0$, where $\rho \Delta \mathrm{FER} \Delta \mathrm{GD}, \rho \Delta \mathrm{MB} \Delta \mathrm{GD}, \rho \Delta \mathrm{BDD} \Delta \mathrm{GD}$ are respectively the correlations between the changes in foreign exchange reserves and the government deposit, the monetary base and the government deposit, the deposit of the Banking Department and the government deposit. $\sigma \Delta \mathrm{FER}, \sigma \Delta \mathrm{GD}, \sigma \Delta \mathrm{MB}, \sigma \Delta \mathrm{BDD}$ are the standard deviations of changes in the foreign exchange reserves, the government deposit, the monetary base and the deposit of the Banking Department.

The condition for stabilization can be expressed through the correlation between the changes in the monetary base and the government deposit $\rho \Delta \mathrm{MB} \Delta \mathrm{GD}$ :

(10) $\rho \Delta \mathrm{MB} \Delta \mathrm{GD}>(\rho \Delta \mathrm{FER} \Delta \mathrm{GD} \sigma \Delta \mathrm{FER}-\rho \Delta \mathrm{BDD} \Delta \mathrm{GD} \sigma \Delta \mathrm{BDD}) / \sigma \Delta \mathrm{MB}$

Since the correlation between the changes in the currency board assets and the government deposit is positive, the correlation between changes in the deposit of the Banking Department and the government deposit is negative, and the standard deviations of the changes in the currency board assets, the deposit of Banking Department and the monetary base are positive, the term on the righthand side of the Inequality (10) is positive. Therefore, the correlation between the changes in the monetary base and the changes in the government deposit should be positive

(11) $0<\rho \Delta \mathrm{MB} \Delta \mathrm{GD} \leq 1$

Inequality (11) imposes strict conditions for the dynamics of the changes in the government deposit and the monetary base - they must always move in the same direction. If their unidirectional dynamics is distorted, it can be argued that the government deposit will have a destabilizing effect on the monetary base (Nenovsky and Hristov, 1998).

For the analyzed period (January 1998 - December 2018) the correlation between the monetary base and the government deposit is -0.07 , which means that the existence of fiscal reserves in the currency board balance sheet has had a weak destabilizing effect on the money supply.

The liquid effect (LE) is an important part of the monetary transmission mechanism and its existence creates conditions for monetary influence on the real macroeconomic variables. If LE is available, money is not neutral in the short run. The liquidity effect can be defined as a fall in nominal interest rates as a result of an exogenous positive shock on the monetary base (Chobanov and Nenovsky, 2004). As prices are rigid in the short term, the rise in the monetary base lowers real interest rates, which causes a restructuring of the portfolios of the business agents and acceleration of economic activity.

The analysis in this article is limited to describing the possible sources of exogenous shocks on the monetary base and measuring the liquidity effect in the conditions of the "soft" Bulgarian currency board. The main source of exogenous shocks on the monetary base in Bulgaria are the changes in the government deposit in the Issue Department of the BNB. The liquidity effect under a CBA can be divided into two types - international and national. The international liquidity effect is triggered by the monetary policy of the central bank, whose currency is used as a reserve currency. The national liquidity effect is related to opportunities of the national fiscal and monetary authorities to influence the monetary base. This divide is largely conditional, as the revenues from state property privatization and the IMF loans that are part of the balance of payments can be considered both international and national sources of shocks on the monetary base (Petrov, 2000).

The presence of a government deposit on the currency board balance sheet gives the Bulgarian government the opportunity to conduct a discretionary monetary policy by fiscal means. The changes in the government deposit directly affect the monetary base and the liquidity in the economy and indirectly the interest rates. Nenovsky and Hristov (1998) found no empirical evidence of an impact of the government deposit on the interbank interest rates, probably because of the very short analyzed period. Petrov (2000), however, concluded that the government deposit generated asymmetric liquidity shocks that the central bank could not compensate, and that the fluctuations in this deposit were the main cause of interest rate fluctuations in the interbank market.

In this study, the definition of LE by Nenovsky, Hristov and Mihaylov (2001) is adopted: "a reduction in nominal interest rates as a result of a positive shock (increase) in the government's fiscal reserves". 
Empirical analysis of the automatic adjustment mechanism of the Bulgarian currency board arrangement

Methodology and data

In the present study, a vector autoregression (VAR) was applied. Monthly data of the Bulgarian National Bank for the period January 1998 - December 2018 were used. All indicators were calculated as a percentage change on the previous month except for MRR, which were given as a percentage of deposits. By the data used (monthly data of the Bulgarian National Bank), the present study resembles the investigations of Nenovsky and Hristov (1998), Nenovsky, Hristov and Mihaylov (2001) and Nenovsky and Hristov (2002).

All variables were tested for stationarity. If it was found that they were integrated of the first order, tests were made for the optimal number of lags and co-integration of Johansen. The optimal number of lags was used in the Johansen test and later in the construction of the vector autoregression. If the Johansen test demonstrated a cointegration link between variables, a restricted VAR, also known as a Vector Error Correction (VEC), was applied. Otherwise, an unrestricted VAR was used.

In the selection of the explanatory variables involved in the vector autoregression, the general characteristics of the currency boards and the specifics of the Bulgarian currency board were taken into account.

Results

The determinants of the monetary base in Bulgaria under a currency board arrangement were identified by a vector autoregression, which included the following variables: MB - monetary base; $\mathrm{BP}$ - balance of payments; GD - government deposit on the balance sheet of the Issue Department of the Bulgarian National Bank; MRR - minimum required reserve ratio of commercial banks. The target variable was MB. All indicators were calculated as a percentage change on the previous month, excluding MRR, which were given as a percentage of commercial bank deposits. Two dummy variables were also included in the model: FAL accounts for the liberalization of the balance of payments financial account in January 2000, and EUM stands for Bulgaria's EU membership since January 2007.

Table 1: Group unit root tests of MB and BP

\begin{tabular}{|l|r|r|r|r|}
\hline \multicolumn{1}{|c|}{ Method } & Statistic & Probability & $\begin{array}{c}\text { Cross- } \\
\text { sections }\end{array}$ & Observations \\
\hline Null: Unit root (assumes common unit root process) & \multicolumn{3}{|c|}{} \\
\hline Levin, Lin \& Chu t* & -4.70754 & 0.0000 & 2 & 394 \\
\hline & & & & \\
\hline Null: Unit root (assumes individual unit root process) & -9.91446 & 0.0000 & 2 & 394 \\
\hline Im, Pesaran and Shin W-stat & 99.9055 & 0.0000 & 2 & 394 \\
\hline ADF - Fisher Chi-square & 220.159 & 0.0000 & 2 & 406 \\
\hline PP - Fisher Chi-square & & & \\
\hline Source: Own calculations
\end{tabular}

Table 2: Group unit root tests of MB, BP, GD and MRR

\begin{tabular}{|l|c|r|r|r|}
\hline \multicolumn{1}{|c|}{ Method } & Statistic & Probability & $\begin{array}{c}\text { Cross- } \\
\text { sections }\end{array}$ & Observations \\
\hline Null: Unit root (assumes common unit root process) & -3.54949 & 0.0002 & 4 & 786 \\
\hline Levin, Lin \& Chu t* & & & & \\
\hline & -16.1685 & 0.0000 & 4 & 786 \\
\hline Null: Unit root (assumes individual unit root process) & 216.066 & 0.0000 & 4 & 786 \\
\hline Im, Pesaran and Shin W-stat & 328.905 & 0.0000 & 4 & 812 \\
\hline ADF - Fisher Chi-square & \multicolumn{5}{|l|}{} \\
\hline PP - Fisher Chi-square & \multicolumn{5}{|l|}{} \\
\hline
\end{tabular}


The unit root test (see Tables 1 and 2) of two groups of variables (first group: MB and BP; second group: MB, BP, GD and MRR) indicated that variables were stationary (integrated of order zero), which lead to the following inferences:

- There was long-term equilibrium neither in the first nor in the second group of variables. This meant that the automatic adjustment mechanism of the Bulgarian currency board worked neither in a pure form (co-integration between $\mathrm{MB}$ and $\mathrm{BP}$ ) nor with elements of discretion (co-integration between MB, BP, GD and MRR);

- To model the relationship between MB, BP, GD and MRR, an unrestricted VAR had to be applied, but not a VEC.

Table 3: Optimal lag length in the VAR model

\begin{tabular}{|c|r|r|r|r|}
\hline Number of lags & \multicolumn{1}{|c|}{ FPE } & \multicolumn{1}{c|}{ AIC } & \multicolumn{1}{c|}{ SC } & \multicolumn{1}{c|}{ HQ } \\
\hline 0 & 1.438459 & 17.39083 & 17.49118 & 17.43146 \\
\hline 1 & 0.000425 & 9.262642 & $9.965095 *$ & $9.547028 *$ \\
\hline 2 & 0.000496 & 9.417156 & 10.72171 & 9.945302 \\
\hline 3 & 0.000629 & 9.652886 & 11.55954 & 10.42479 \\
\hline 4 & 0.000639 & 9.663360 & 12.17212 & 10.67903 \\
\hline 5 & 0.000710 & 9.761346 & 12.87221 & 11.02077 \\
\hline 6 & 0.000481 & 9.360948 & 13.07391 & 10.86413 \\
\hline 7 & $0.000230 *$ & $8.606669 *$ & 12.92174 & 10.35362 \\
\hline 8 & 0.000260 & 8.707831 & 13.62500 & 10.69854 \\
\hline \multicolumn{2}{|r}{} & * Shows the optimal number of lags according to the respective criterion \\
\hline
\end{tabular}

Source: Own calculations

The optimal lag length test showed that according to the Schwarz and Hannan-Quinn criteria this length was one lag (see Table 3). The vector autoregression was estimated with one lag.

The equation for the target variable MB in the VAR model after the step-by-step removal of the statistically insignificant variables was

(12) $\mathrm{MB}=0.059-0.345 * \mathrm{MB}(-1)-0.004 * \mathrm{MRR}(-1)$

The results from the estimation of Equation (12) were shown in Table 4.

Table 4: Results from the estimation of Equation (12)

\begin{tabular}{|c|r|r|r|r|}
\hline Variable & \multicolumn{1}{|c|}{ Coefficient } & \multicolumn{1}{|c|}{ Standard error } & \multicolumn{1}{c|}{ t-Statistic } & \multicolumn{1}{c|}{ Probability } \\
\hline Constant (intercept) & 0.058989 & 0.023508 & 2.509341 & 0.0129 \\
\hline MB(-1) & -0.344800 & 0.065960 & -5.227399 & 0.0000 \\
\hline MRR(-1) & -0.004444 & 0.002458 & -1.807799 & 0.0721 \\
\hline
\end{tabular}

Source: Own calculations

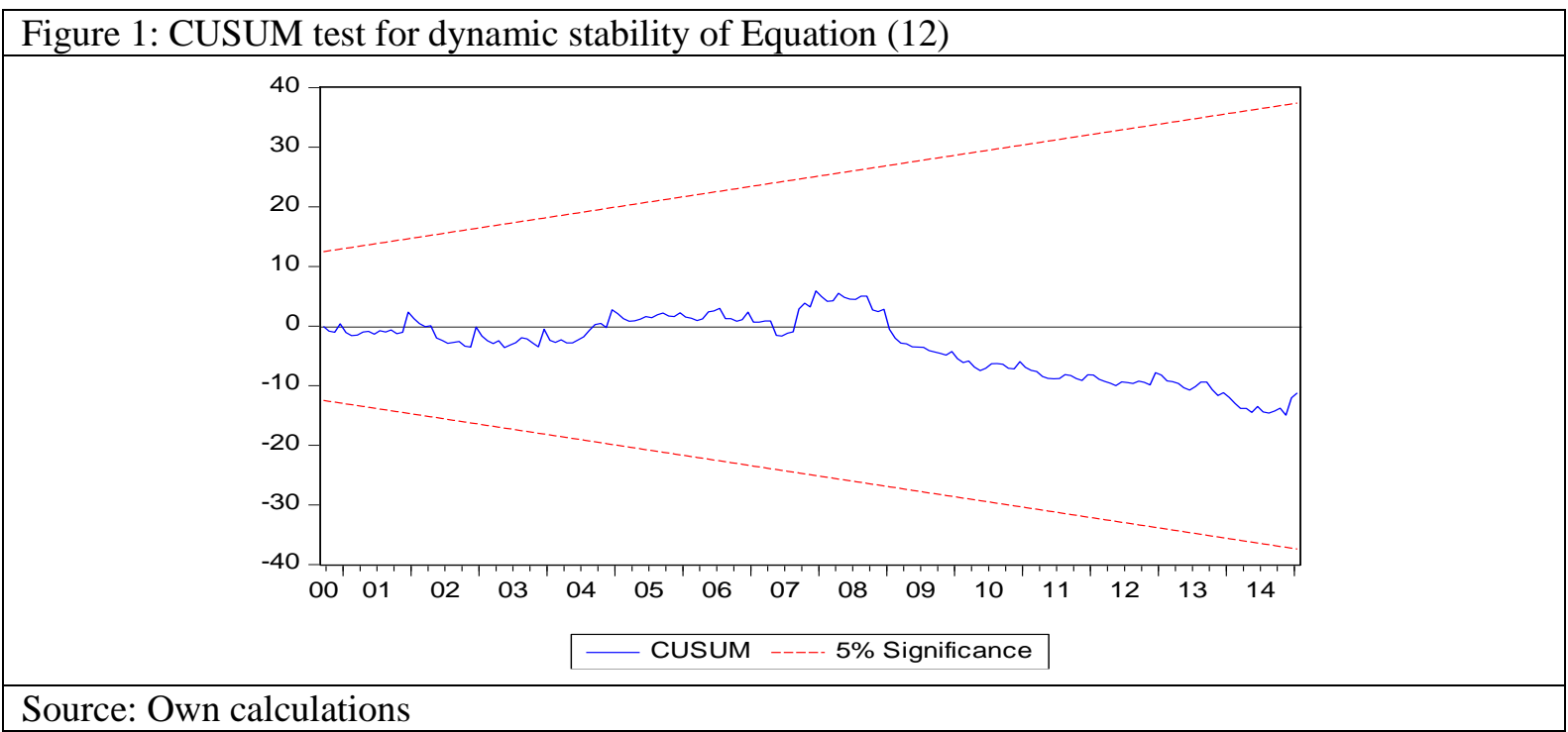


The percentage rate of change of the monetary base was influenced by its own past value and the past value of MRR. The only significant variable allowing for a monetary discretion was MRR.

The value of the coefficient of determination $(\mathrm{R}$-squared $=0.13$ ) showed that $13 \%$ of the percentage rate of change of Bulgaria's monetary base could be explained by changes in the independent variables involved in Equation (12). The probability of the F-statistic $(0,00)$ indicated that the alternative hypothesis of adequacy of the model used was confirmed. However, it had to be made clear that this did not mean that the model was the best possible, but simply adequately reflected the relationship between the dependent and the independent variables.

The results of the CUSUM test indicated that Equation (12) was dynamically stable (see Figure 1) since the actual CUSUM values were within the confidence interval at the 5\% level of significance. The results of the Ramsey test (probability of the F-statistic 0.1462) gave reason to accept the null hypothesis of lack of errors in the specification of Equation (12).

\section{Empirical study of the impact of the changes in the government deposit on the money market}

Methodology and data

A VAR methodology was used to determine the impact of the government deposit GD on the interbank interest rate IR. Monthly data were used for the period February 1998 - December 2018. The government deposit (the fiscal reserve) was calculated as a percentage change on the previous month.

The unit root tests (see Table 5) indicated that the variables were stationary as a group, which required the application of an unrestricted VAR.

\begin{tabular}{|c|c|c|c|c|}
\hline Method & Statistic & Probability & $\begin{array}{c}\text { Cross- } \\
\text { sections }\end{array}$ & Observations \\
\hline \multicolumn{5}{|c|}{ Null: Unit root (assumes common unit root process) } \\
\hline Levin, Lin \& Chu $t^{*}$ & -2.85369 & 0.0022 & & 387 \\
\hline \multicolumn{5}{|c|}{ Null: Unit root (assumes individual unit root process) } \\
\hline Im, Pesaran and Shin W-stat & -12.1665 & 0.0000 & & 387 \\
\hline ADF - Fisher Chi-square & 114.179 & 0.0000 & & 387 \\
\hline PP - Fisher Chi-square & 112.364 & 0.0000 & & 406 \\
\hline \multicolumn{5}{|l|}{ Source: Own calculations } \\
\hline
\end{tabular}

The optimal lag number test showed that according to the Phillips-Peron and Akaike criteria, this number was six (see Table 6). The VAR model was estimated with six lags.

\begin{tabular}{|c||r|r|r|r|}
\hline \multicolumn{1}{|l|}{ Table 6: Optimal lag length in the VAR model } \\
\hline Number of lags & FPE & AIC & \multicolumn{1}{|c|}{ SC } & \multicolumn{1}{c|}{ HQ } \\
\hline 0 & 393.5529 & 11.65097 & 11.68442 & 11.66451 \\
\hline 1 & 91.61193 & 10.19331 & $10.29366^{*}$ & 10.23394 \\
\hline 2 & 89.09603 & 10.16545 & 10.33270 & $10.23316^{*}$ \\
\hline 3 & 92.43400 & 10.20219 & 10.43634 & 10.29698 \\
\hline 4 & 93.71356 & 10.21587 & 10.51692 & 10.33775 \\
\hline 5 & 94.62920 & 10.22548 & 10.59344 & 10.37445 \\
\hline 6 & 83.18806 & 10.09647 & 10.53132 & 10.27252 \\
\hline 7 & 86.14272 & 10.13116 & 10.63291 & 10.33429 \\
\hline 8 & 88.14645 & 10.15388 & 10.72253 & 10.38410 \\
\hline
\end{tabular}

Results

The equation for the target variable IR in the VAR model after the step-by-step elimination of the statistically insignificant variables was

(13) $\operatorname{IR}=0.78 * \operatorname{IR}(-1)+0.21 * \operatorname{IR}(-4)-0.43 * \operatorname{IR}(-5)+0.39 * \operatorname{IR}(-6)+0.07$

The results from the estimation of Equation (13) were shown in Table 7. 


\begin{tabular}{|c|r|r|r|r|}
\hline \multicolumn{1}{|c|}{ Table 7: Results from the estimation of Equation (13) } \\
\hline Variable & \multicolumn{1}{|c|}{ Coefficient } & Standard error & \multicolumn{1}{c|}{ t-Statistic } & \multicolumn{1}{c|}{ Probability } \\
\hline Constant (intercept) & 0.070954 & 0.083998 & 0.844710 & 0.3993 \\
\hline IR(-1) & 0.776413 & 0.048999 & 15.84551 & 0.0000 \\
\hline IR(-4) & 0.212958 & 0.069410 & 3.068105 & 0.0025 \\
\hline IR(-5) & -0.429528 & 0.078262 & -5.488364 & 0.0000 \\
\hline IR(-6) & 0.394290 & 0.065227 & 6.044846 & 0.0000 \\
\hline \multicolumn{5}{|l}{} \\
\hline Source: Own calculations
\end{tabular}

The interest rate on the interbank market was influenced by its values in previous periods, but not by the dynamics of the government deposit. The value of the determination coefficient (R-squared $=0.83$ ) showed that $83 \%$ of the interbank interest rate change in Bulgaria could be explained by its lag values. The Probability of the F-statistic (0.00) indicated that the alternative hypothesis of adequacy of the model used was confirmed. However, it had to be made clear that this did not mean that the model was the best possible, but simply adequately reflected the relationship between the dependent and the independent variables.

The results of the CUSUM test indicated that Equation (13) was dynamically stable (see Figure 2) since the actual CUSUM values were within the confidence interval at the $5 \%$ level of significance.

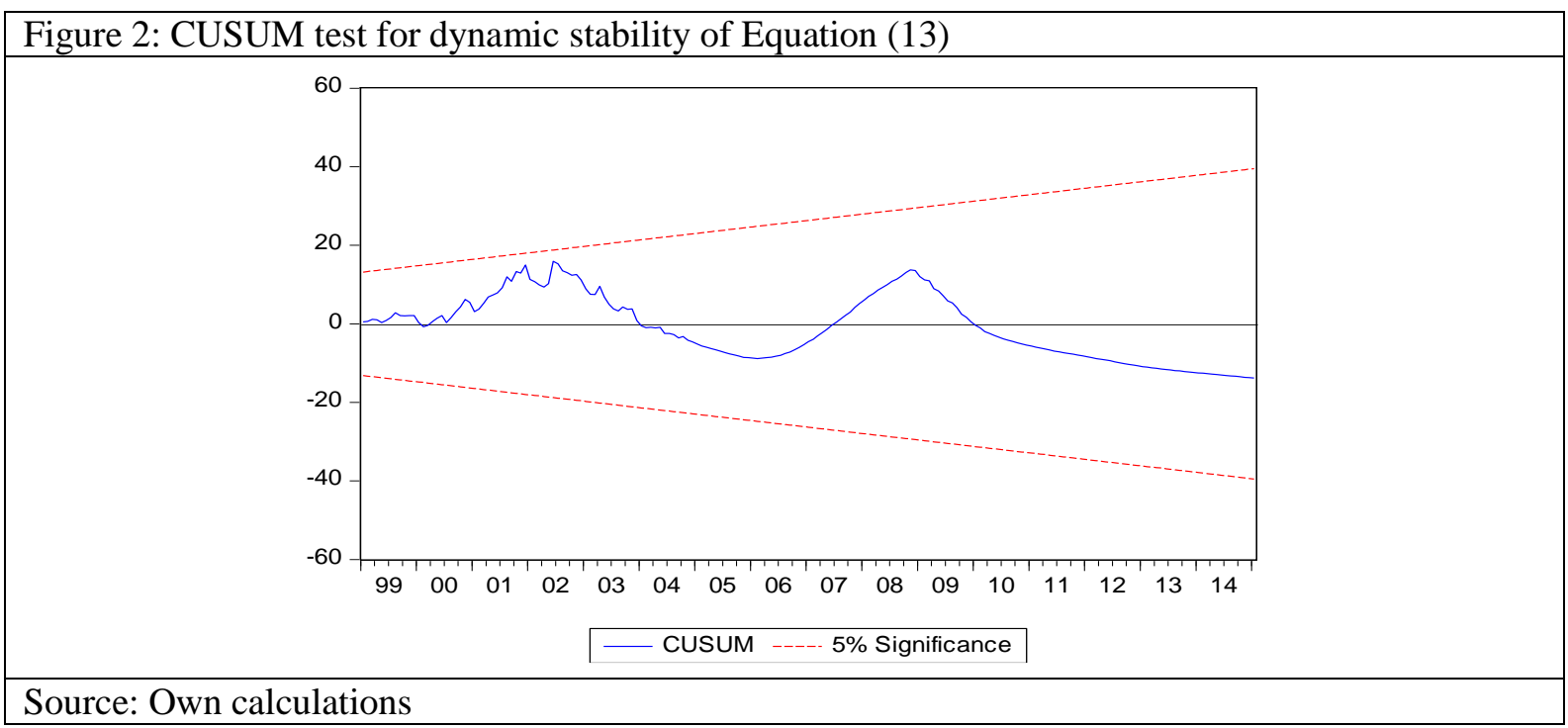

The results of the Ramsey test (probability of the F-statistic 0.1899) gave reason to accept the null hypothesis of lack of errors in the specification of Equation (13).

\section{Conclusion}

The three research objectives stated in introduction were achieved.

In fulfillment of the first objective of the study, it was found that the automatic adjustment mechanism of the Bulgarian currency board does not function either in a pure form (cointegration between MB and $\mathrm{BP}$ ) or with elements of discretion (cointegration between MB, BP, GD and MRR). The percentage rate of change of the monetary base is affected by its previous value and the size of the MRR. The opportunities for a discretionary impact on the monetary base under the conditions of the Bulgarian currency board are related to a change in the MRR. No evidence has been found of a statistically significant effect of the government deposit in the currency board liabilities on the monetary base.

As to the second objective of the study, for the period of investigation (January 1998 - December 2018) the correlation between the monetary base and the government deposit was calculated to be 0.07 , which implied that the existence of fiscal reserves in the currency board balance sheet had a weak destabilizing effect on the monetary base.

In regard to the third goal of the study, no proof of a statistically significant influence of changes in the government deposit on the interbank interest rate was established for the analyzed period 1998-2018. 
The empirical results of this study did not confirm the hypothesis of a liquidity effect existence in the conditions of the Bulgarian currency board.

The comparison of this research with other studies on the same or similar topic such as Nenovsky and Hristov (1998), Nenovsky and Hristov (2002) and Nenovsky, Hristov and Mihaylov (2001) lead to the following inferences:

- By the methodology employed (VAR), the present study resembles the investigations of Nenovsky and Hristov (1998) and Nenovsky, Hristov and Mihaylov (2001) and differs from the research of Nenovsky and Hristov (2002), which used a cointegration analysis/error correction;

- Unlike the other three studies, this research found no evidence of a statistically significant impact of the changes in the government deposit in the Bulgarian National Bank on the monetary base;

- All four investigations concurred that the automatic adjustment mechanism of the Bulgarian CBA did not function in its pure form (as a cointegration between the balance of payments and the monetary base);

- According to Nenovsky and Hristov (2002) and Nenovsky, Hristov and Mihaylov (2001), the automatic adjustment mechanism of the Bulgarian CBA worked with elements of discretion (when the deposit of government was included in the model). However, the present study found no proof of cointegration between the balance of payments, the monetary base and the government deposit).

It may be concluded that although a possibility exists for the Bulgarian government to conduct discretionary monetary policy by fiscal means, no empirical proof of such policy was found for the period of investigation January 1998 - December 2018.

\section{References}

Avramov, R. (1999). The Role of a Currency Board in Financial Crises: The Case of Bulgaria. BNB Discussion Papers, DP/6/1999.

Carlson, J. A. \& Valev, N. T. (2001). Credibility of a New Monetary Regime: The Currency Board in Bulgaria. Journal of Monetary Economics, 47(3): 581-594.

Chobanov, P. and Nenovsky, N. (2004). Money Market Liquidity under Currency Board - Empirical Investigations for Bulgaria. William Davidson Institute Working Paper Number 693, May 2004.

Desquilbet, J. B. \& Nenovsky, N. (2004). Credibility and Adjustment: Gold Standards Versus Currency Boards. William Davidson Institute Working Paper Number 692, May 2004.

Dobrev, D. (1999). The currency board in Bulgaria: design, peculiarities and management of foreign exchange cover. Discussion papers / Bulgarian National Bank. - Sofia, ZDB-ID 2169813-2. - Vol. 9

Fabris, N. \& Rodic, G. (2013). The Efficiency of the Currency Board Arrangement. Journal of Central Banking Theory and Practice, 2013 (1): 157-176.

Gulde, A. (1999). The Role of the Currency Board in Bulgaria's Stabilization. IMF Policy Discussion Papers 99/3.

Hanke, S. \& Schuler, K. (1991). Teeth for the Bulgarian Lev: A Currency Board Solution. Washington, D.C.: International Freedom Foundation.

Hardouvelis, G. A. \& Monokrousos, P. (2009). Is Bulgaria's Currency Board Sustainable? Economy \& Markets, Eurobank Research, Volume 4, Issue 7, July 2009.

Hristov, K. (2004). The currency board: ,the only game in town”. BNB Discussion Paper, DP/40/2004 (in Bulgarian).

Ialzanov, D. \& Nenovsky, N. (2001). The Currency Board and Bulgaria's Accession to the European Monetary Union. Kyoto University Economic Review, 70(1/2): 31-48.

Kielyte, J. (2002). Exchange Rate Arrangements in the Run-up to the EMU: Some Experience in Currency Board Countries. EERI Research Paper Series EERI_RP_2002_01, Economics and Econometrics Research Institute (EERI), Brussels.

Kiguel, M. A. (1999). The Argentine Currency Board. CEMA Working Papers: Serie Documentos de Trabajo. 152, Universidad del CEMA.

Marinova, T. (2016). Comparative Study on Monetary and Fiscal Policy in the Eurozone and Bulgaria. Economic Alternatives, 2016(3): 367-378.

Miller, J. B. (1999). The Currency Board in Bulgaria: The First Two Years. BNB Discussion Papers, DP/11/1999.

Minassian, G. (2018). Two decades of currency board in Bulgaria: how much more? In: "Bulgaria in Europe: lagging behind or catching up. Strategies for catch-up development". Institute for New Economic Thought, Sofia, pp. 60-98 (in Bulgarian).

Moheeput, A. (2008). Issues on the choice of Exchange Rate Regimes and Currency Boards - An Analytical Survey. WARWICK ECONOMIC RESEARCH PAPERS No 855. 
Nenovsky, N. and Dimitrova, K. (2002). Dual Inflation Under the Currency Board: The Challenges of Bulgarian EU Accession. William Davidson Institute Working Papers Series 487, William Davidson Institute at the University of Michigan. Nenovsky, N. and Hristov, K. (1998). Financial Repression and Credit Rationing under Currency Board Arrangement for Bulgaria. BNB Discussion Papers, DP/2/1998.

Nenovsky, N. and Hristov, K. (2002). The new currency boards and discretion: empirical evidence from Bulgaria. Economic Systems 2002 (26): 55-72.

Nenovsky, N., Hristov, K. and Mihaylov, M. (2001). A SIMPLE TEST OF CURRENCY BOARD AUTOMATIC

MECHANISM IN BULGARIA, ESTONIA AND LITHUANIA. Journal des Economistes et des Etudes Humaines, XI (4): 575-616.

Nenovsky, N., Hristov, K. and Mihaylov, M. (2002). Comparing the Institutional and Organizational Design of Currency Boards in Transition Countries. Eastern European Economics, 40(1): 6-35.

Petrov, B. (2000). Bank Reserves Dynamics under Currency Board in Bulgaria. Bulgarian National Bank Discussion Paper, DP/15/00.

Todorov, I. (2013). The Bulgarian Currency Board Arrangement in the Context of the Future Membership of Bulgaria in the Euro Area. Ikonomicheski i sotsialni alternativi, 2013(3): 112-124 (in Bulgarian). 